\section{CLINICAL LECTURES ON}

\author{
MENTAL AND CEREBRAL DISEASES.
}

BY J. CRICITON BROWNE, M.D., F.R.S.E., Medical Dircctor, West Riding Asylum; Lccturer on Mental Diseases to the J.ceds School of Medicine; etc.

\section{II. - IIYSTERical Mania.-(Concluded.)}

WHAT, then, are the symptoms of this well marked type of mental disease called hysterical mania? Some of these have been already brought before you in connexion with the cases introduced, but it may be well to give a separate and succinct sketch of them. The preludes to the attack are generally debility, with defective appetite and menstrual disorder. The attack itself begins suddenly, either without any warning, or after a few days of depression or silent reserve. Loquacity and restlessness are its earliest and most permanent symptoms. Philo. sophers have asserted that women possess a superiority over men in their powers of conversation; and this remark is powerfully confirmed by the disease under consideration. The untiring vigour with which a delicate-looking girl will talk incessantly for twenty-four hours is positively amazing. She seems to gather strength as she goes on; for, as the disease advance., volubility becomes greater. The utterances thus fluently poured forth are at first disjointed, but rational sentences; inopportune, but sharp and comprehensible remarks; and then mere broken and interjectional phrases. The incoherence in this disorder, however, is never comparable with that of acute mania, even in its worst phases, as some shreds of sense may be found in it; some laws of association may be observed to regulate it. In the midst of a torrent of what sounds meaningless chattering, you will be surprised by some clever or pertinent expression-some words that prove that memory is active, and that perception is acute. Very soon after talkative excitement is established, it assumes an emotional complexion. This is happy and joyous, and there are fits of laughter and musical outbursts ; or pensive and sad, and there are profusive tears and convulsive chokings. Most frequently these emotional states alternate with each other, while the mind is gradually sicklied over with the pale cast of eroticism. In a great majority of cases, the morbid excitement of what has been called the tender emotion is distinctly observable. There is increased agitation produced by the presence of a member of the opposite sex; there are rhapsodies addressed to some real or ideal lover; there are sentimental cravings; there are passionate invocations; there are lascivious movements, obscene speeches, and even filthy acts; and along with these erotic manifestations there are perverse and mischievous propensities. Dugald Stewart said that women surpass men in docility and aptitude to learn. After watching a few cases of hysterical mania, you will see reason to doubt at least the first part of that statement. The intractability, obstinacy, and noisy spitefulness displayed are truly disheartening to those who have to deal with them. In the worst cases, there are also destructiveness, violence, and degraded habits, and perverted appetites leading to consumption of cinders or garbage. Throughout the disease, however, in the worst cases as well as the mildest, a peculiar power of rallying is generally preserved. Selfcontrol is not altogether lost. The current of excitement can be stemmed for a few seconds. A degree of intelligence can be exhibited which seems incompatible with such decided mania. As the excitement diminishes and recovery is approached, there is either depression of spirits, listless indifference, or acute sensitiveness. In some cases, there are confusion of thought, a sense of bewilderment, and an obliteration of memory as regards the whole or large portions of the attack.

Along with these mental symptoms there are, at the beginning of hysterical mania, headache (often limited to the frontal region), loss of appetite, and muscular tremor. In a few cases there is also spinal tenderness in the dorsal region, with pains in the abòomen and legs. Pallor of the countenance and dilatation of the pupils are always present. The pulse is only slightly increased in frequency; the skin is cool and moist ; and the tongue clean, or only coated with a thin white fur. There is usually a profuse flow of light-coloured limpid urine. A very fair amount of sleep is obtained; but, as the attack progresses, this gradually lessens in amount, until, at its height, the whole night is perhaps passed without even a snatch of rest. As sleep is reduced in quantity, cutaneous sensibility is heightened, until a state of general or local hyperæsthesia is attained. The slighiest touch causes, or seems to cause, sharp pain. This condition, however, is not constant, but comes and goes, and is occasionally replaced by anæsthesia or bluntness of feeling. 'There is invariably muscular restlessness throughout the whole stage of excitement. The play of features, or rather the contortion of the face, is constant and inexhaustible. All sorts of gestures and gesticulations are practised. Spasms and twitchings affect the voluntary muscles, and sometimes the involuntary ones also, producing choking, hiccup, and griping pains. Not rarely there is a vehement trembling of the eyelids, and also palpitation of the heart. The excitement and rapid movements cause some acceleration of the pulse and elevation of temperature, but ordinarily the pulse and temperature undergo less change than might have been anticipated. A sudden and transitory rise in either may happen without any obvious explanation, but their average range is tolerably normal. As the attack proceeds, constipation of the bowels comes on, as well as menstrual irregularity, if that has not existed before the incursion of the insanity. Throughout the whole attack, the body retains its plumpness in an almost miraculous manner. Notwithstanding that little food is taken, and that wear and tear are excessive, emaciation is warded off. When convalescence is reached, weakness is much complained of, and also frequently the pain under the left breast, first described by Dr. Todd, and referred by him to reflex sensation. If I might venture in any way to amend what has been stated by so eminent an authority as Dr. Todd, I would tell you that this pain is felt more in the splenic than in the submammary region; and that it is in a few cases associated with profound anæmia, without leucorrhcea. Along with this pain, during convalescence after hysterical mania, there are occasionally gastrodynia of a severe kind, and various erratic neuralgic pains. Respecting the duration of an attack of hysterical mania, I can give you no reliable information. In some cases, it terminates in a few days; in others, it continues for months. It is rarely, however, that any one attack, even when unmodified by treatment, lasts more than three months.

To bring more practically before you, in the concrete, what I have told you about hysterical mania, or at least part of what I have told you, I shall now recall to you the case of S. M., aged I8, single, a dressmaker from Leeds, who was discharged recovered on the I $4_{\text {th }}$ of December last. This girl had been a pupil-teacher in a Wesleyan school, and had applied very closely to her studies and passed her examination creditably at sixteen years of age, when all at once her health failed and she became melancholy and hysterical. She was then sent to the country, and in about six weeks became quite strong again. Up till August last she was in good health and employed as a dressmaker. Then, however, she became weak and pale and ill, and was noticed to be more sensitive than was her wont. No specific ailment could be discovered, but her debility grew upon her until the beginning of September, when she became quiet and dejected. In this state she remained for two days, and then suddenly launched out into vociferous cheerfulness, which passed through various stages of aggravation, and finally necessitated her incarceration in this asylum on the 2oth of September. One cousin of hers had been insane, and another epileptic. Her mother had always been nervous. Out of five brothers and sisters of hers, four had died in infancy. When admitted here she was talking in a loud tone of voice and rambling manner upon many subjects, interlarded with fragments of texts and prayers. She understood what was said to her, answered questions, only too glibly and copiously, and could remain quiet for a little when ordered peremptorily to do so. She insisted upon pacing up and down and tossing her arms about. She said she had pain on the right side of her head and "all down the spine of her back", so that she could not lean upon a chair nor allow the skin over the vertebrx to be pressed or rubbed. She was of average height, exceedingly pale with fair hair and widely dilated pupils; the skin was moist. There was slight increase of vocal resonance over the apices of both lungs, and the heart-sounds were loud and widely diffused. During the night of the 2oth she slept well, but as soon as she awoke on the morning of the 2 Ist recommenced to vociferate. She also wept and laughed, and could not be persuaded to take much food. On the 28th September she is reported as somewhat more composed, and as having taken abundant nourishment, but being so weak as to be unable to stand. On the 3 oth she is said to be very excitable and unmanageable; also more incoherent and destructive, having torn up some clothing and flowers in the airing-court. A specimen of her incoherence was taken down cerbatim, and I now read it to you. "Gold, silver, waxworks, yellow, pink, and white--Get a substitute-Reverend So and So-Plenty of law-givers-Two brothers-Bible-Eternal life and death-A man I love to honour-Honour to whom honour is due - My master-Give him a life pill-Self praise is no recommendation -Venerable old age-Fox and Pitt."-All this, and endless quantities of the same stuff, with the most extraordinary volubility. On October Ist, the entry is in the case-book:-Pulse 90 ; tongue clean; takes her food indifferently, talking incoherently, but remains in bed. On the 2nd it is:- Has been much excited all day, crying out in a loud harsh voice; very emotional; attitudinises and throws herself into tragica. 
postures ; is alternately erotic and religious in her conversation, love, however, being her chief theme. Pulse $\mathrm{I} 30$; tongue clean; bowels have not acted for two days. On October 3 rd, Has had some broken sleep; very incoherent and mischievous; raves mostly about some one named "Cavosa," to whom she refers in amorous terms; pulse 120. On October 4 th, Is a little quieter; pulse 123, and irritable; pupils much contracted; face pale ; tongue clean. On October I2th, Is decidedly improved ; capable of rational conversation; has not menstruated for six weeks. On October 23rd, Still improving, but very weak ; is quiet and downcast; employed in sewing. After this she gained ground steadily until the date of her discharge.

No difficulty attends the differential diagnosis of hysterical mania. It could only be confounded with acute mania, and the excited stage of acute dementia. From the former it is distinguished by its history, by the less deep and universal involvement of the mind which characterises it, by the character of the delirium, by the moisture of the skin and comparative cleanness of the tongue and unaltered state of the secretions, by the absence of great muscular strength or rigidity and of rapid emaciation, and by the slightness of the modification of the pulse and temperature; from the latter it may be known by the absence of the stupidity and fatuity which mark the delirium of acute dementia, and of that chilled and livid state of the hands, feet, and features, which accompanies it.

The prognosis of hysterical mania is equally simple with its diagnosis, and is invariably favourable. The tendency of the disease is to end in recovery. But this tendency may be fostered and encouraged, and the duration of the disease much curtailed by judicious treatment. The only danger to be apprehended is that of relapse; but this is sometimes considerabie, as many as five and six relapses taking place in one case.

Fortunately, there is no morbid anatomy of hysterical mania. In one case only have I seen death occur in consequence of an intercurrent condition. That, however, was the most inveterate and distinctive case of hysterical mania that I ever encountered, and I shall therefore read to you the notes of the sectio cadaveris as far as they bear upon our present subject. The skull was of average thickness, but unsymmetrical, bulging posteriorly to the left. On removing it, the dura mater was seen to be tense, without folds or wrinkles, as if it were tightly stretched over the brain. On opening it, the brain expanded and bulged over the sawn edge of the skull as if it had been subjected to compression. The whole brain weighed forty-six ounces. There was very slight thickening of the arachnoid. The gyri were plump and in close apposition to each other. The grey matter was extremely pale, especially in its deeper layers, which were scarcely distinguishable from the medullary substance, which was of unusually firm consistence. The ventricles were of average size and contained no fluid. A small round body, of firm gelatinous consistence and about the size of a pea, lay imbedded at the anterior end of the third ventricle, fastened there by little fibrous attachments. The middle commissure was of extraordinary thickness and strength. The floor of the fourth ventricle was congested. The neck of the uterus was much enlarged and indurated. The left ovary was of the size of a large walnut, and was converted into a fibrous capsule containing dark fluid contents and one large clot. There was a cyst at the outer extremity of the left Fallopian tube.

The treatment of hysterical mania requires a careful adaptation to varying conditions. Its occasionally transitory nature justifies a trial of home-treatment before an asylum is resorted to ; but if under hometreatment it remain unabated at the end of fourteen days, then removal should not be any longer delayed. The most protracted and troublesome cases that have fallen under my observation have been those in which home-treatment had been persevered in for months, until patience had been exhausted. The prolongation of the disease increases the risk of relapse, so that it is of much importance to cut it short at the earliest possible moment. During the maniacal condition there is not much room for moral treatment. A conciliatory and yet firm manner on the part of the physician, however, is not without its effect. Quietness and rest are also advantageous, and any simple occupation, such as sewing, if its adoption can be secured during an interval of tranquillity, is often very useful. It fixes attention, and by its very monotony soothes the perturbed mind. Exercise in the fresh air ought to be taken daily, and nourishing food must be administered. The medical treatment I generally begin with is a mixture containing bromide of potassium and tincture of valerian-forty grains of the former and a drachm of the latter in each dose, to be taken three or four times a day. This has sometimes a most gratifying effect, as in the case of $\Lambda$. H., who was perfectly well four days after her admission here. If, however, its beneficial action be not very speedily manifested, no good will result from continuing its employment. I should recom- mend you, then, to resort to morphia and assafotida. From a quarter to half a grain of the muriate of morphia with from ten to thirty grains of assafœetida may be given twice or thrice a day. The tincture of assafoetida is not objected to in pauper asylums. This treatment is generally successful ; but should it fail, as it sometimes will, then cannabis Indica with bromide of potassium ought to be tried. This valuable combination was brought into notice in the Annales Médico-Psychologiques in 1867 . We have employed it here constantly since then, and with decisive benefit in many cases. The use of narcotics is not contraindicated in hysterical mania. Warm, tepid, and even cold shower, baths are sometimes composing and useful. During convalescence, iron is almost always required, sometimes quinine also. I have a particularly high opinion of the value of Easton's syrup of the phos. phates of iron, quinine, and strychnia, during recovery from hysterical mania. Of course, menstrual disorders must be subjected to their appropriate treatment.

\section{THE HASTINGS PRIZE ESSAY,} I870.

\section{ON DIGITALIS: ITS MODE OF ACTION AND ITS USE.*}

By J. MILNER FOTHERGILL, M.D., Late Senior Resident Medical Officer to the Public Dispensary, Leeds.

Drugs of similar Power. - The whole question of agents acting upon the heart so as to increase its power of contraction is comparatively new. With the exception of digitalis we are, generally speaking, scarcely acquainted with their names. The agents are either entirely new, or nothing has hitherto been known of their secondary effect upon the heart. The list of them is a short one, and will not take up much space in the enumeration. Thus Dr. Clifford Allbutt has advocated the use of Virginian cherry-juice (Prunus Virginiana) in cardiac affections; Dr. John Harley has investigated the action of belladonna; Dr. Braidwood the action of dajasck, or arrow-poison of Borneo (Tanghanina venenifera); Drs. Hilton Fagge and Stevenson have investigated the action of the Scilla maratina and the Hellebornts viridis; and Leven has investigated caffein and thein. Of these, the writer has only experimented on digitalis, belladonna, and caffein. There is thus plenty of opportunity for investigating further the action of these drugs, and adding to what we already know of their action; while there is a ground for hope that to this list may be added new agents more certain, more effective, and more manageable than those we as yet possess. It is, then, with the hope and expectation that such will be the case that the writer has devoted so large a space to the consideration of the mode of action of digitalis. He has striven to aggregate what is known of the subject, and his own more recent conclusions, in order that the question may be regarded as broadly as possible. The frequent digressions and the consideration of the action of the morbid process have sometimes been considered at greater length than the administration of the agent; as, once admitting the increase in the activity of the ventricular contraction as the chief therapeutic action of the agent, the question of the value of the agent must rest on the question as to how far increased ventricular contraction may or may not be beneficial. By thus treating digitalis as a member of a class of agents, it will much facilitate the investigation into the usefulness, or uselessness, of a drug as a cardiac neurotic. It is obvious that other agents which increase the ventricular contraction and bring the heart to a standstill in systole, must necessarily possess a therapeutic value allied to that of digitalis. In prosecuting such an inquiry, it will be easy to ascertain to what extent the action is common to that of the whole class, or in what it is singular. This grouping of agents as to action will assist us in aggregating a number of agents with either a primary or secondary effect upon the heart ; in time this will constitute a group, and in practice the remote effect of an agent upon the heart will be taken into consideration in the choice of therapeutic agents. Thus, we as yet can merely guess to what extent the different actions of opium and belladonna, as hypnotics, may be dependent, as regards the success or non-success following their administration, on the vascularity of the brain. How far the beneficial effect of belladonna, at times when opium has failed to relieve, may rest directly, not on the different hypnotic alkaloid, but on the vascular supply of the brain being augmented by its use, we know not. Thus a series of experiments with belladonna in

\footnotetext{
* Concluded from page ir 6 of last number.
} 